\title{
Keep the ball rolling
}

\section{Many people around the world will remember 2014 as the year Brazil hosted the football World Cup. But for Brazil's science communities, the decisions made by the new government could leave scars much deeper than the semi-final defeat.}

For a country that established its first graduate physics programmes in the 1960s, Brazil has made impressive progress to earn its current position on the international physics scene. One could argue that the first step on this journey was not a decision taken by the government, but by the state of São Paulo. Its use of one per cent of state tax receipts to launch its own research agency, Fundação de Amparo à Pesquisa do Estado de São Paulo (FAPESP), laid important foundations that continue to be relevant today.

Although two federal funding agencies were already in existence at the time Conselho Nacional de Desenvolvimento Científico e Tecnológico (CNPq) and Coordenação de Aperfeiçoamento de Pessoal de Nível Superior (CAPES) FAPESP was more focused on funding projects, rather than individuals, and provided a continued source of crucial support. With the addition of Financiadora de Estudos e Projetos (FINEP) in the late 1960s, a federal funding agency providing support for both industry and academia, the foundations were in place for Brazil to develop its domestic science base.

During the 1970s and 1980s, physics departments were created across the country's rapidly expanding federal university system. Although the infrastructure was starting to fall into place, the economic environment of the late 1980s and 1990s provided extremely challenging conditions. Federal funding was squeezed, reaching fever pitch when FAPESP, which continued to have the backing of state tax receipts, had more money than CNPq and FINEP combined.

Following this tough period the new century was much kinder, and science in Brazil continued its impressive march. Under the presidency of Luiz Inácio Lula da Silva, known popularly as Lula, the National Science and Technology Institutes programme, which was first set up with the aid of the World Bank, was rapidly expanded. This meant many institutes could be funded on a much more consistent basis. Such stability, along with a science budget that increased fivefold to reach $1.2 \%$ of GDP, helped propel Brazilian physics to the international arena.

Such was the health of Brazilian physics that by the time Dilma Rousseff became the country's first female president in 2011, Sociedade Brasileira de Física (the Brazilian physics society) had around 6,000 members, the country had close to $4,000 \mathrm{PhD}$ physics students and Brazilian physicists were publishing over 5,000 articles per year. Brazil was also looking likely to be the first Latin American country to become an official member of CERN, and was poised to become the first non-European member of the European Southern Observatory.

\section{Although Brazil is one of the top ten richest countries in the world, its investment in research and development still falls well below other developed nations.}

But as one might expect for a country where science is so young, many challenges remain. Although there are several worldrenowned physicists in Brazil, most still struggle to reach such heights and the country's research papers often fail to attract citations from the rest of the world. With such a rapid rise in scientific output, this is perhaps not surprising. And it is surely only a matter of time before this 'impact gap' is bridged. But this is assuming that the federal government and states continue their support. And although Brazil is one of the top ten richest countries in the world, its investment in research and development still falls well below other developed nations who typically spend $2-3 \%$ of GDP.

With such remarkable progress and so much potential, Brazilian scientists were extremely disappointed to see Dilma Rousseff's government slashing the federal science budget by almost a third during its first two years in office ${ }^{2}$. Although the level of funding has since recovered, such cuts have taken a heavy toll on Brazil's progress and ultimately led to an unhelpful degree of uncertainty in the scientific communities.

Unfortunately, science also did not feature prominently in the build-up to the recent elections in October, despite a leading candidate, Eduardo Campos, being one of
Lula's former science ministers. Tragically, Eduardo Campos died in a plane crash in August.

When the elections took place on 5 October 2014, no single party was able to secure an overall majority, so a runoff between the top two candidates was scheduled for 26 October. The two candidates were Aécio Neves of the PSDB (Social Democracy Party) and Dilma Rousseff from the PT Workers' Party. The future of science under either candidate is not clear, but Aécio Neves has promised to roll back government spending and provide the stability his party offered during their last stint in government. It was Lula's predecessor, PSDB's Fernando Henrique Cardoso, who helped to stabilize the economy after the difficult 1990s and, some would argue, allowed Lula's government to transform social, economic and science conditions. The environment under the Cardoso and Lula regimes seems a far cry from the declining economic growth, state interventionism and severe budget cuts seen under Dilma Rousseff - conditions that led to riots in the build up to the football World Cup.

With so much uncertainty, Brazilian state governments are now following the lead of São Paulo and forming their own research councils. FAPESP is a real success story and has helped to make São Paulo a powerhouse, accounting for over half of all of Brazil's scientific output and housing over $20 \%$ of the countries scientists. Furthermore, São Paulo hosts the Brazilian synchrotron light laboratory, the Universidade de São Paulo is one of the main institutions involved in the Large Latin American Millimeter Array, and São Paulo State University will soon become part of Intel's parallel computing progamme ${ }^{3}$. In the hope of emulating this success, there are now more than 15 state-level funding agencies. But it is clear that federal funding will continue to play a key role. Brazilian scientists can only hope that the incoming federal government will look to the remarkable success São Paulo has enjoyed, and set Brazilian physics back on course.

\footnotetext{
References

1. Jorio, A. et al. Nature Mater. 9, 528-531 (2010).

2. Amorim, L. Nature http://doi.org/wdv (2012).

3. Orwig, J. Physics Today (September 2014);

http://go.nature.com/jyabdb
} 